\title{
The Role of Autologous Stem Cell Transplantation in the Treatment of Diffuse Large B-Cell Lymphoma
}

\author{
Marco Gunnellini, ${ }^{1}$ Rita Emili, ${ }^{1}$ Stefano Coaccioli, ${ }^{2}$ and Anna Marina Liberati1 \\ ${ }^{1}$ Department of Transplant Oncohematology, Perugia University, S. Maria, Terni, Italy \\ ${ }^{2}$ Faculty of Medicine, Perugia University, S. Maria, Terni, Italy \\ Correspondence should be addressed to Anna Marina Liberati, marinal@unipg.it
}

Received 15 October 2011; Accepted 15 November 2011

Academic Editor: Ian Magrath

Copyright (C) 2012 Marco Gunnellini et al. This is an open access article distributed under the Creative Commons Attribution License, which permits unrestricted use, distribution, and reproduction in any medium, provided the original work is properly cited.

\begin{abstract}
Diffuse large B-cell non-Hodgkin's lymphoma (DLBCL) accounting for approximately 30\% of new lymphoma diagnoses in adult patients. Complete remissions (CRs) can be achieved in $45 \%$ to $55 \%$ of patients and cure in approximately $30-35 \%$ with anthracycline-containing combination chemotherapy. The ageadjusted IPI (aaIPI) has been widely employed, particularly to "tailor" more intensive therapy such as high-dose therapy (HDT) with autologous hemopoietic stem cell rescue (ASCT). IPI, however, has failed to reliably predict response to specific therapies. A subgroup of young patients with poor prognosis exists. To clarify the role of HDT/ASCT combined with rituximab in the front line therapy a longer follow-up and randomized studies are needed. The benefit of HDT/ASCT for refractory or relapsed DLBCL is restricted to patients with immunochemosensitive disease. Currently, clinical and biological research is focused to improve the curability of this setting of patients, mainly young.
\end{abstract}

\section{Introduction}

Diffuse large B-cell non-Hodgkin's lymphoma (DLBCL) is the commonest histological subtype of non-Hodgkin's lymphomas (NHL) accounting for approximately $30 \%$ of new lymphoma diagnoses in adult patients. Because their incidence increases in old age, this epidemiological pattern might explain, at least in part, the rapid rise in the number of new diagnoses observed over the last decades of the 20th century $[1,2]$ in which an increase of median age of population has also been registered.

Complete remissions (CRs) can be achieved in $45 \%$ to $55 \%$ of patients and cure in approximately $30-35 \%$ with anthracycline-containing combination chemotherapy [3].

The International Prognostic Index (IPI) proposed in the 1993 [4] has been used in the risk stratification for patients with DLBCL for more than a decade. The age-adjusted IPI (aaIPI) has also been widely employed, particularly to "tailor" more intensive therapy such as high-dose therapy (HDT) with autologous hemopoietic stem cell rescue (ASCT). IPI, however, has failed to reliably predict response to specific therapies. This, in part, reflects the inherent biological heterogeneity of DLBCL and highlights the need for more precise, patient-specific, and biologically based risk factors. Despite these criticisms, the IPI has proved valuable for stratification of patients in clinical trials and remains the prognostic system more widely employed in clinical research and daily practice.

The development of rituximab, a chimeric anti-CD20 monoclonal antibody, has represented a revolutionary advance in the therapy of hematologic malignancies [5]. The addition of rituximab to cyclophosphamide, doxorubicin, vincristine, and prednisone (CHOP) combination has produced significant survival benefits in elderly patients with untreated DLBCL compared to CHOP alone [6, 7]. Similarly, the same immunochemotherapy regimen has determined an improved outcome in young low-risk DLBCL patients [8], as defined by aaIPI. Thus, first line chemotherapy with $\mathrm{CHOP}$ or CHOP-like regimens in combination with rituximab has become standard care for CD20+ DLBCL patients.

Despite the striking advances in the outcome of DLBCL patients, a subgroup of young patients with poor prognosis still exists $[9,10]$. Currently, clinical and biological research is focused to improve the curability of this setting of patients, mainly young. 


\section{HDT with ASCT in Front-Line Treatment of DLBCL}

In the prerituximab era, HDT/ASCT has proven effective as salvage treatment in patients with chemosensitive relapsed aggressive NHL [11]. These results suggested the possibility of improving the outcome of aggressive NHL patients by including HDT/ASCT in the first-line therapy. After some phase I/II trials supporting the use of this strategy, HDT/ASCT appeared a promising option for frontline treatment of young patients. However, the results of prospective randomized trials [12-25] have generated conflicting results and several problems have hampered the comparison of data (Tables 1 and 2).

Firstly, trials had different remission status requirements for HDT/ASCT [12-25]. In particular, only patients in PR or $\mathrm{CR}$, after induction therapy (Table 1), were randomized to receive HDT/ASCT or conventional therapy [12-16]. Secondly, in other trials, patients were randomized at diagnosis (Table 2), and HDT/ASCT was employed as part of initial treatment after shortened [19-21,25] or full course of induction therapies [17, 18, 22-24]. Furthermore, high-dose sequential (HDS) therapy, a type of induction treatment based on a different "philosophy" from the rationale underlying the conventional one, was administered up-front followed by HDT/ASCT in three studies [17, 23, 24]. HDS therapy consists in the administration of several non-crossresistant drugs, each given at the maximal tolerated dose mainly as single agent within the shortest possible interval. The purpose of this regimen was to prevent the emergence of drug-resistant tumor clones. Thirdly, a great variety of therapeutic regimens, both among conventional or highdose treatments, were employed. In fact, conventional CHOP regimen or CHOP-like combinations were employed in 3 and 6 trials, respectively, while, in the other studies, MACOP$B$ or VACOP-B were used $[17,18,21,22]$. Although the combination of carmustine, etoposide, cytarabine, and melphalan (BEAM) was the most frequently employed conditioning regimen $[15,16,18-20,22,25]$, other myeloablative treatments $[12-14,17,21,23,24]$ were also used in several trials. Fourthly, because several of these studies were designed before the introduction in the clinical practice of both the IPI prognostic score [4] and the REALWHO histological classification [26], trials included varying proportions of patients with different risk categories and different histological subtypes, not all of which were DLBCL. Despite the poor comparability of these trials, a statistically significant prolongation of PFS or EFS was documented in four trials $[15,19,22,25]$, but none demonstrated a significant improvement of OS associated with HDT/ASCT with the exception of a retrospective subgroup analysis [14]. In summary, in the prerituximab era, HDT/ASCT, employed in front-line therapy, failed to improve the outcome of aggressive NHL patients.

In the rituximab era, HDT/ASCT for intermediate-high (I-H) or high-risk (H) aaIPI patients is still a matter of debate. However, the combination of rituximab with an intensified treatment strategy has resulted in encouraging results in phase II studies (Table 3). Tarella et al. [27] used rituximab in combination with modified HDS chemotherapy delivered with multiple ASCT followed by a consolidation phase consisting of mitoxantrone (Mito) and melphalan (L-PAM) with ASCT. In this study, 93 of the 112 patients enrolled completed the planned therapy. At conclusion of treatment, the CR rate was $80 \%$. At a median followup of 48 months, the estimated 4-year OS projection was $76 \%$ (CI: $68-85 \%$ ), and at median followup of 46 months, the 4-year EFS projection was 73\% (CI: 64-81\%). Vitolo et al. [28] employed 4 cycles of dose-dense $(110 \mathrm{mg} / \mathrm{mq}$ epirubicin, $1200 \mathrm{mg} / \mathrm{mq}$ ciclofosfamide, $1.4 \mathrm{mg} / \mathrm{mq}$ vincristina, and $40 \mathrm{mg} / \mathrm{mq}$ prednisone orally days 1 to 5 given every two weeks) CEOP regimen as induction phase, followed by the 2 cycles of mitoxantrone, cytarabine, and dexamethasone (MAD) as intensification phase. The third phase of study design consisted of BEAM with ASCT. A total of six rituximab doses were given, 4 and 2 during induction and intensification phases, respectively. Seventy six of the 94 patients completed treatment and underwent HDT/ASCT. The CR rate was $82 \%$ (CI: 73-88\%). With a median followup for censored patients of 49 months, the 4-year FFS rate was $73 \%$ (CI: $63,5-82,5 \%$ ) and the 4 -year OS rate was $80 \%$ (CI: 71, 6-88,4\%). Dilhuydy et al. [29] reported an overall response (OR) rate of $67 \%$. With a median followup of 66 months, the estimated rates $( \pm \mathrm{SD})$ of 5 -year OS and EFS rates were $74 \% \pm 4 \%$ and $55 \% \pm 5 \%$, respectively. Fitoussi et al. [30] treated 208 patients with rituximab combined with cyclophosphamide, vindesine, bleomycin, and prednisolone (ACVBP) for 4 cycles. This induction therapy was followed by BEAM with ASCT in 155 responding patients (CR or PR). A total of 32 patients did not receive HDT/ASCT. Twenty five were withdrawn during induction therapy, 6 because of insufficient response before consolidation and one because of sudden death. With a median followup of 45 months, the 4 -year PFS and OS were estimated at 76\% (CI: 69-81\%) and $78 \%(72-83 \%)$.

In both the Vitolo and the Fitoussi studies, the results achieved with the immunochemotherapy strategy were compared with those obtained in their historical groups of patients treated with similar sequence of chemotherapy program, but not including rituximab. Despite the limitations intrinsic to retrospective analyses, these comparisons showed a clear therapeutic advantage of immunotherapy over chemotherapy in both the two major end points PFS and OS.

Recently two randomized studies conducted by the SWOG [31] and FIL [32] have tested the role of HDT/ASCT in the front line therapy of unfavorable $(\mathrm{I}-\mathrm{H} / \mathrm{H})$ patients with aggressive NHL. In particular, in the SWOG study, patients responsive to the $\mathrm{CHOP}$ or $\mathrm{R}-\mathrm{CHOP}$ induction therapy were randomized to receive one more cycle of R-CHOP followed by TBI or BCNU-based regimens and ASCT or three additional cycles of R-CHOP [31]. In this trial, the $2 \mathrm{yr}$ PFS was $69 \%$ and $56 \%$ in the experimental arm compared to the standard one (95\% CI: $1.18-2.51) P=0.05$, while no significant difference was documented in the 2-year OS. The authors conclude that HDT/ASCT improves PFS for responders, including those induced with R-CHOP, with a stronger outcome seen for those with H IPI grade. The FIL study, a multicenter randomized trial with a $2 \times 2$ factorial 


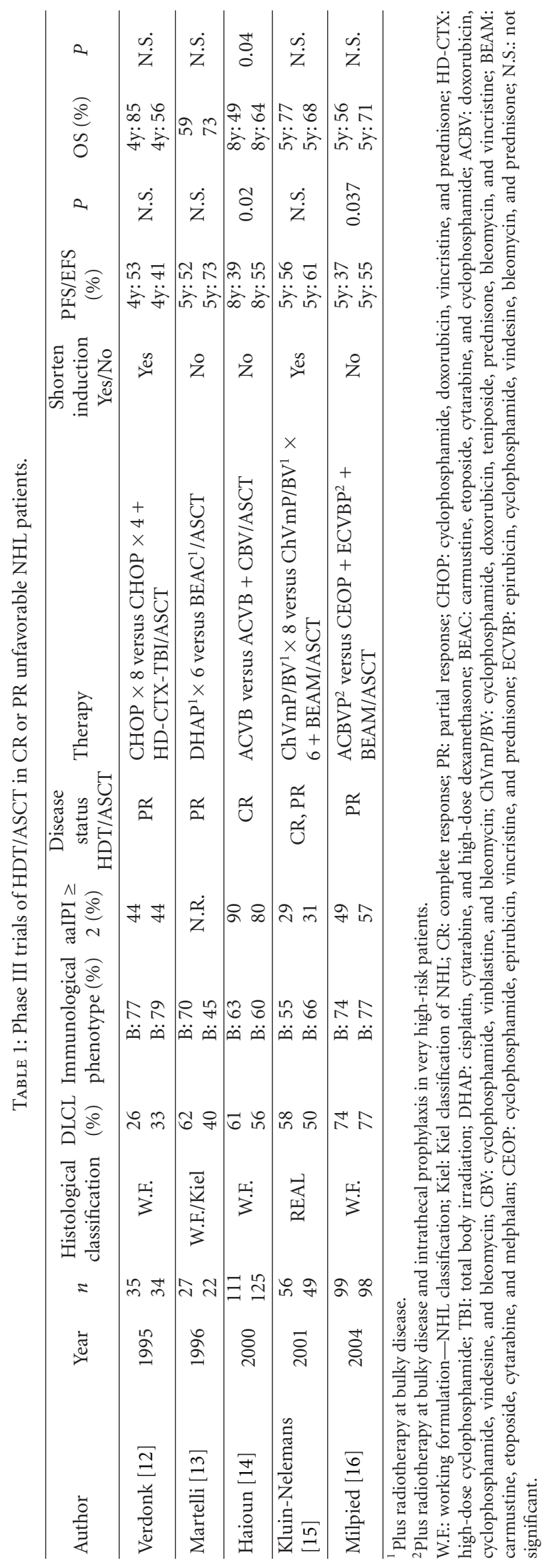




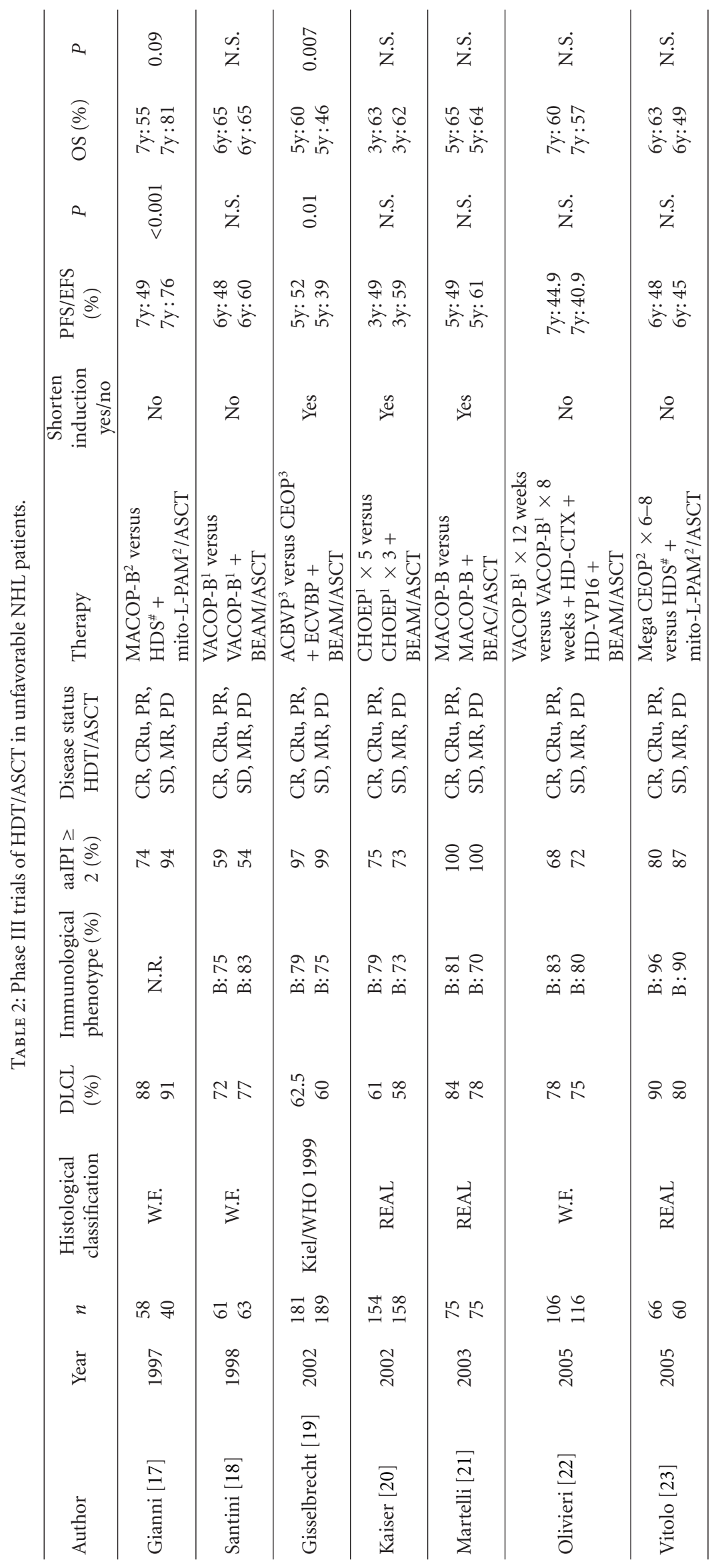




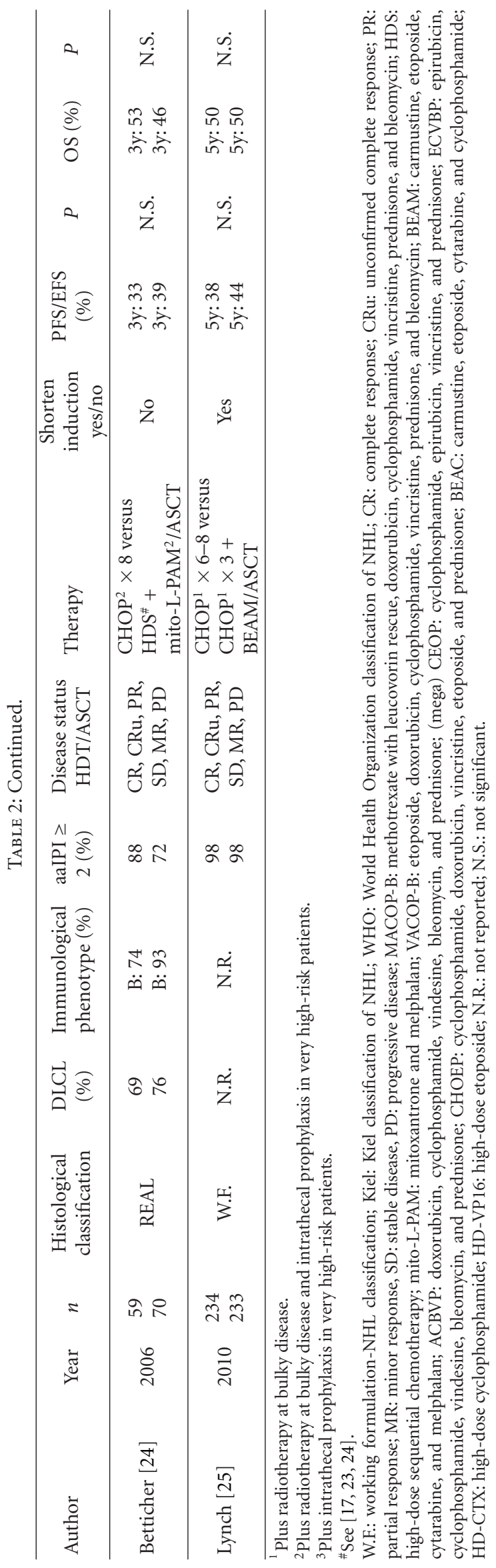


TABLE 3: Studies of HDT/ASCT in unfavorable DLBCL patients.

\begin{tabular}{|c|c|c|c|c|c|c|c|c|c|c|}
\hline Author & Year & $n$ & $\begin{array}{l}\text { Pathological } \\
\text { phenotype }\end{array}$ & $\begin{array}{l}\text { DLCL } \\
(\%)\end{array}$ & $\begin{array}{l}\text { Immunological } \\
\text { phenotype (\%) }\end{array}$ & $\begin{array}{c}\text { aaIPI } \geq \\
2(\%)\end{array}$ & Therapy & $\begin{array}{c}\text { Shorten } \\
\text { induction } \\
\text { yes/no }\end{array}$ & $\begin{array}{c}\text { PFS/EFS } \\
(\%)\end{array}$ & $\begin{array}{l}\text { OS } \\
(\%)\end{array}$ \\
\hline Tarella [27] & 2007 & 112 & REAL & 79 & B. 100 & 100 & Modified R-HDS"\#1 & No & $4 y: 73$ & $4 y: 76$ \\
\hline Vitolo [28] & 2009 & 97 & REAL & 86 & B. 100 & 100 & $\begin{array}{l}\text { R-mega CEOP } 14 \times \\
4+\mathrm{R}^{-M_{A}}{ }^{2} \times 2+ \\
\text { BEAM/ASCT }\end{array}$ & No & $4 y: 73$ & $4 y: 80$ \\
\hline Dilhuydy [29] & 2010 & 42 & REAL & N.R. & B. 100 & 100 & $\begin{array}{l}\mathrm{R} \times 4+\mathrm{CEEP} \times 2+ \\
\mathrm{R}-\mathrm{MTX} / \mathrm{R}-\mathrm{MC}+ \\
\mathrm{BEAM} / \mathrm{ASCT}\end{array}$ & Yes & $5 y: 55$ & $5 y: 74$ \\
\hline Fitoussi [30] & 2011 & 209 & WHO & N.R. & B. 100 & 100 & $\begin{array}{l}\text { R-ACVBP } \times 4+ \\
\text { BEAM/ASCT }\end{array}$ & Yes & $4 y: 76$ & $4 y: 78$ \\
\hline
\end{tabular}

${ }^{1}$ Plus radiotherapy at bulky disease.

${ }^{2}$ Plus radiotherapy at bulky disease and intrathecal prophylaxis in very high-risk patients.

\#See [26].

REAL: revised European-American lymphoma classification; WHO: World Health Organization classification of NHL; R: rituximab; (mega) CEOP: cyclophosphamide, epirubicin, vincristine, and prednisone; MAD: mitoxantrone, cytarabine, and dexamethasone; BEAM: carmustine, etoposide, cytarabine, and melphalan; CEEP: cyclophosphamide, epirubicin, vindesine, and prednisone; MTX: methotrexate; MC: methotrexate and cytarabine; ACBVP: doxorubicin, cyclophosphamide, vindesine, bleomycin, and prednisone; N.R.: not reported.

design, compared two rituximab dose-dense treatments ( $\mathrm{R}$ CHOP14 versus R-megaCHOP14), followed or not by BEAM with ASCT [32]. With a median followup of 23 months, 2year PFS was 65\% (CI: 59-70\%), for the entire group of enrolled patients and 59\% (CI: $51-57 \%$ ) versus 72\% (CI: 64-78\%) for no HDT/ASCT versus HDT/ASCT respectively. So far, the advantage in PFS does not translate in OS benefit. However, a longer followup will clarify the role of HDT/ASCT as first-line treatment of aaIPI 2-3 DLBCL patients. These and other randomized studies will define whether HDT/ASCT combined with rituximab in the front line therapy is associated with increased cure rate of unfavorable DLBCL patients.

\section{HDT with ASCT as Salvage Therapy}

In the prerituximab era, the Parma trial established HDT/ ASCT as standard therapy in relapsing aggressive NHL patients responding to salvage therapy [11].

The parameters affecting the results of HDT/ASCT are identified in responsive disease to conventional dose salvage therapy before myeloablative treatment, relapse defined as a time less than twelve months from diagnosis to recurrence (early), and the presence of prognostic factors at relapse, as defined by IPI or secondary aaIPI (saaIPI) [33-35].

At present, the emphasis of recent clinical research in HDT/ASCT is focused on three therapeutic aspects. The first consists in the evaluation of the potential benefit of adding rituximab to salvage therapy, followed by HDT/ASCT, in relapsed rituximab naïve patients. Overall, the available data in this setting of patients, although not completely concordant, are in favour of the use of immunochemotherapy (Table 4). In first three studies reported in Table 4, no patient [36] or only a minority of cases $[37,38]$ had received rituximab before enrollment, while, in the fourth, $25 \%$ of patients were treated with rituximab in the first line therapy or during salvage treatment or both at diagnosis and after relapse [39]. In the Kewalramani et al. study, the PFS rates of patients who underwent HDT/ASCT after ICE in combination with rituximab (RICE) were marginally improved compared to those observed in the historical control patients who received salvage therapy alone [36]. The difference was not statistically significant, but the study was not powered to detect minor improvements in survival rates. However, in this study, the addition of rituximab to ICE doubled the percentage of CRs. Sieniawski et al., in their study reported improved OR rate, freedom from second failure (FF2F), and OS in the patient group treated with DHAP plus rituximab, compared to the historical control group treated with the same chemotherapy [37]. In both groups, patients in CR or PR after salvage therapy received HDS therapy followed by BEAM with ASCT. Improved FFS and PFS were documented also by Vellenga et al. [38] in relapsed patients when rituximab was added to DHAP-VIM-DHAP reinduction therapy. The modest impact of rituximab on OS was amplified when the analysis was repeated adjusting for prognostic factors such as time elapse since upfront treatment, saaIPI score, age, and WHO PS. Furthermore, the addition of rituximab increased the group of responders on reinduction therapy from $54 \%$ to $74 \%$ and therefore the number of patients who might benefit from HDT/ASCT. In this study, as well, only patients in CR or PR after salvage therapy were eligible for HDT/ASCT. In the Mounier et al. study [39], after HDT/ASCT, the 5-year OS was 63\% (95 CI, 58-67\%), and the 5-year DFS was $48 \%$ (95 CI, 43-53\%) for the entire population. Statistical analysis indicated a significant increase in DFS after ASCT compared with duration of CR I (median, 51 months versus 11 months; $P<.001)$. This difference remained highly significant in patients with previous exposure to rituximab (median, 10 months versus not reached; $P<0.01$ ). The second aspect regards the role of rituximab in salvage treatment of patients previously treated with immunochemotherapy (Table 5). In fact, at present, almost all patients with aggressive B-cell NHL are initially treated with rituximab in association with $\mathrm{CHOP}$ or CHOP-like regimens. In these patients, the role of rituximab in further salvage treatment remains to be 
TABLE 4: Rituximab-based salvage therapy in rituximab-naïve relapsing/refractory DLBCLs.

\begin{tabular}{|c|c|c|c|c|c|c|c|c|c|c|}
\hline Author & Year & $n$ & $\begin{array}{l}\text { Pathological } \\
\text { phenotype }\end{array}$ & $\begin{array}{c}\text { DLCL } \\
(\%)\end{array}$ & Therapy & $\begin{array}{l}\text { Conditioning } \\
\text { regimen }\end{array}$ & $\begin{array}{c}\text { PFS/EFS } \\
(\%)\end{array}$ & $P$ & OS $(\%)$ & $P$ \\
\hline Kewalramani [36] & 2004 & $\begin{array}{c}36 \\
147\end{array}$ & WHO & 100 & $\begin{array}{l}\text { R-ICE } \\
\text { ICE }\end{array}$ & $*$ & $\begin{array}{l}2 y: 54 \\
2 y: 43\end{array}$ & N.S. & $\begin{array}{l}2 y: 67 \\
2 y: 56\end{array}$ & N.S. \\
\hline Sienawski [37] & 2007 & $\begin{array}{l}19 \\
19\end{array}$ & WHO & 80 & $\begin{array}{l}\text { R-DHAP }{ }^{1} \\
\text { DHAP }^{1}\end{array}$ & BEAM & $\begin{array}{l}2 y: 57 \\
2 y: 18\end{array}$ & 0.0051 & $\begin{array}{l}2 \mathrm{y}: 77 \\
2 \mathrm{y}: 37\end{array}$ & 0.0051 \\
\hline Vallenga [38] & 2008 & $\begin{array}{l}113 \\
112 \\
\end{array}$ & WHO & $\begin{array}{l}80.5 \\
78.6 \\
\end{array}$ & $\begin{array}{l}\text { R-DHAP-VIM-DHAP } \\
\text { DHAP-VIM-DHAP }^{1}\end{array}$ & BEAM & $\begin{array}{l}2 y: 52 \\
2 y: 31\end{array}$ & 0.002 & $\begin{array}{l}2 y: 59 \\
2 y: 52\end{array}$ & N.S. \\
\hline Mounier [39] & 2011 & 470 & WHO & 100 & N.R. & $\begin{array}{l}\text { BEAM and } \\
\text { others }^{\#}\end{array}$ & $5 y: 48$ & $0.001^{* *}$ & $5 y: 63$ & N.R. \\
\hline
\end{tabular}

${ }^{1}$ Plus radiotherapy at bulky disease.

*The choice of conditioning regimen depended on the patient's age, the extent of previous therapy and the clinical trials active at the time of transplantation (see [30]).

\#See [39].

**Each patient was assessed as his or her own control.

WHO: World Health Organization classification of NHL; R: rituximab; ICE: ifosfamide, carboplatin, and etoposide; DHAP: cisplatin, cytarabine, and dexamethasone; VIM: etoposide, ifosfamide, and methotrexate; BEAM: carmustine, etoposide, cytarabine, and melphalan; N.R.: not reported; N.S.: not significant.

TABLE 5: Salvage therapy in relapsing/refractory DLBCLs previously exposed to rituximab.

\begin{tabular}{|c|c|c|c|c|c|c|c|c|c|c|c|}
\hline Author & Year & $\begin{array}{l}\text { Kind of } \\
\text { study }\end{array}$ & $n$ & $\begin{array}{l}\text { Pathological } \\
\text { phenotype }\end{array}$ & $\begin{array}{c}\text { DLCL } \\
(\%) \\
\end{array}$ & Therapy & $\begin{array}{c}\text { Conditioning } \\
\text { regimen }\end{array}$ & $\begin{array}{c}\text { PFS/EFS } \\
(\%)\end{array}$ & $P$ & OS (\%) & $P$ \\
\hline Martín [40] & 2008 & Retrospective & $\begin{array}{l}94 \\
69\end{array}$ & WHO & 100 & $\begin{array}{l}\text { R-ESHAP (prior R) } \\
\text { R-ESHAP (no prior R) }\end{array}$ & $*$ & $\begin{array}{l}3 y: 17 \\
3 y: 57\end{array}$ & 0.008 & $\begin{array}{l}3 y: 38 \\
3 y: 67\end{array}$ & 0.004 \\
\hline Fenske [41] & 2009 & Retrospective & $\begin{array}{l}818 \\
176 \\
\end{array}$ & WHO & 100 & $\begin{array}{l}\text { R-CT (no prior R) } \\
\text { R-CT (prior R) }\end{array}$ & $*$ & $\begin{array}{l}3 y: 50 \\
3 y: 38\end{array}$ & 0.008 & $\begin{array}{l}3 y: 57 \\
3 y: 45\end{array}$ & 0.006 \\
\hline Gisselbrecht [42] & 2010 & Perspective & $\begin{array}{l}194 \\
202 \\
\end{array}$ & WHO & 100 & R-DHAP R-ICE & BEAM & $\begin{array}{l}3 y: 42 \\
3 y: 31\end{array}$ & N.S. & $\begin{array}{l}2 y: 51 \\
2 y: 47\end{array}$ & N.S. \\
\hline
\end{tabular}

* The choice of conditioning regimen depended on the patient's age, the extent of previous therapy, and the clinical trials active at the time of transplantation (see $[40,41])$.

WHO: World Health Organization classification of NHL; R: rituximab; ESHAP: etoposide, methylprednisolone, cisplatin, and cytarabine; CT: multiple variable regimes; ICE: ifosfamide, carboplatin, and etoposide; DHAP: cisplatin, cytarabine, and dexamethasone; BEAM: carmustine, etoposide, cytarabine, and melphalan; N.S.: not significant.

determined. In the GEL/TAMO report by Martín and colleagues [40], no significant differences in response rates were documented in multivariate analysis between patients treated with R-ESHAP and previously exposed or not to rituximab. However, patients who had received prior rituximab had a significantly worse PFS and OS than rituximab naïve patients. Furthermore, prior treatment with this monoclonal antibody was also an independent adverse prognostic factor for both PFS and OS. In the experience of Fenske et al. [41], the administration of rituximab given with first-line or salvage therapy prior to HDT/ASCT was associated with PFS and OS at 3 years superior to that observed when this monoclonal antibody was not employed during the entire therapeutic patient history. In the CORAL trial [42], the response rates after salvage therapy were affected by several independent factors. These include saaIPI score, short relapse time from diagnosis ( $<12$ months), and prior rituximab treatment. These same independent factors negatively influenced the 3-year EFS, PFS, and OS. However, patients relapsing after more than 12 months from diagnosis benefited from the introduction of rituximab into their salvage regimen and showed 3-year EFS ranging from $40 \%$ to $50 \%$. In conclusion, at present, the optimal second-line regimen is not defined, and the benefit of the inclusion of standard dose of rituximab in salvage therapy for patients previously exposed to this agent is also unclear although known risk factors might be useful in choosing salvage therapeutic strategy. These factors include saaIPI, response (CR versus PR refractory) to upfront therapy disease status (early versus late relapse) at the time of salvage therapy. The third aspect regards the development of resistance to rituximab. One possibility in overcoming this resistance consists in using high-dose (HD) of this antibody. This therapeutic aspect was evaluated by Khouri et al. [43]. HD-rituximab (HD-R) was employed after mobilization chemotherapy and again on day 1 and day 8 after HDT/ ASCT. In this study, the HDT consisted of standard BEAM. Fifty-nine patients $(88 \%)$ were exposed before to rituximab during salvage chemotherapy. The median time from last rituximab dose to study enrollment was 38 days. The results of this experience indicate that HD-R combined with HDT/ASCT is feasible and effective treatment in relapsed patients previously treated with immunotherapy.

An attempt to develop more effective therapeutic strategy for relapsed DLBCL patients consists in the combination of radioimmunotherapy (RIT) with the standard chemotherapy conditioning regimens. After Press et al. [44], first established the feasibility of high-dose RIT with ASCT, several studies have used myeloablative RIT with promising results. 
The RIT combined with high-dose chemotherapy was superior compared to historical data especially in the salvage of patients with high IPI scores and residual PET-avid disease [45]. To further increase the therapeutic potential of RIT, Winter et al. [46] tested dose-escalated ${ }^{90} \mathrm{Y}$-ibriyumumab tiuxetan combined with BEAM and ASCT. In this study, 30\% and $36 \%$ of the 44 treated patients had achieved less than a PR to their most recent treatment or never had obtained CR. Thus, respectively, 30\% of cases would not have been eligible for HDT/ASCT at most centers. The estimated 3-years PFS and OS reported in this unfavorable series of patients were $43 \%$ and $60 \%$, respectively. Careful dosimetry rather than weight-based strategy for dose escalation was required to avoid toxicity and under treatment.

Finally, one relevant prognostic factor associated with DLBCL consists of the cell origin of malignant cells [4751]. In fact, the gene expression profile (GEP) resembling that of germinal center B cells (GCB) is predictive of better patient outcome than a profile resembling that of activated $\mathrm{B}$ cells (ABC). Cell-of-origin (COO) algorithms [52, 53] can also translate GEP data into practical applications. In the prerituximab era, studies using conventional dose therapy or HDT/ASCT concluded in favour of predictive prognostic value of COO $[48,51]$. In contrast, the clinical significance of DLBCL subtyping, as defined by COO, is more controversial in patients treated at diagnosis with immunochemotherapy [53-56]. At relapse, few data regarding the clinical impact of COO-subsets are available. Recently a subanalysis of Coral trial [57] has indicated that COO retains its prognostic value in relapse/refractory DLBCL patients. In addition, a better response to R-DHAP was documented in GCB-like DLBCL cases. In contrast with these findings, in the study by $\mathrm{Gu}$ et al. [58], COO failed to predict survival in DLBCL patients, either with chemosensitive or chemoresistant disease, treated with HDT/ASCT. Further studies are needed to clarify the predictive value of DLBCL subtyping in the setting of patients with refractory/relapsing disease.

In conclusion, the benefit of HDT/ASCT for refractory or relapsed DLBCL is restricted to patients with immunochemosensitive disease. In fact, the response to secondline treatment seems to predict patient outcome after HDT/ ASCT.

Different therapeutic approaches are required to salvage patients with disease resistant to rituximab and chemotherapy. New agents such anti-CD20 antibodies therapeutically more active than rituximab, radiolabeled-antibodies, histone deacetylase inhibitors, various molecules which target mTOR, inhibitor of protein Kinase $C \beta$, and other types of target therapy might be effective in controlling refractoryrelapsing DLBLC.

\section{References}

[1] H. Tilly and M. Dreyling, "Diffuse large B-cell non-Hodgkin's lymphoma: ESMO clinical practice guidelines for diagnosis, treatment and follow-up," Annals of Oncology, vol. 21, no. 5, pp. v172-v174, 2010.

[2] P. Boffetta, "Epidemiology of adult non-Hodgkin lymphoma," Annals of Oncology, vol. 22, supplement 4, pp. iv27-iv31, 2011.
[3] R. I. Fisher, E. R. Gaynor, S. Dahlberg et al., "Comparison of a standard regimen (CHOP) with three intensive chemotherapy regimens for advanced non-Hodgkin's lymphoma," New England Journal of Medicine, vol. 328, no. 14, pp. 1002-1006, 1993.

[4] M. A. Shipp, D. P. Harrington, J. R. Andersen et al., "A predictive model for aggressive non-Hodgkin's lymphoma," New England Journal of Medicine, vol. 329, no. 14, pp. 987-994, 1993.

[5] C. Traullé and B. B. Coiffier, "Evolving role of rituximab in the treatment of patients with non-Hodgkin's lymphoma," Future Oncology, vol. 1, no. 3, pp. 297-306, 2005.

[6] B. Coiffier, E. Lepage, J. Brière et al., "Chop chemotherapy plus rituximab compared with chop alone in elderly patients with diffuse large-B-cell lymphoma," New England Journal of Medicine, vol. 346, no. 4, pp. 235-242, 2002.

[7] P. Feugier, A. Van Hoof, C. Sebban et al., "Long-term results of the R-CHOP study in the treatment of elderly patients with diffuse large B-cell lymphoma: a study by the groupe d'etude des lymphomes de l'adulte," Journal of Clinical Oncology, vol. 23, no. 18, pp. 4117-4126, 2005.

[8] M. Pfreundschuh, L. Trümper, A. Österborg et al., "CHOP-like chemotherapy plus rituximab versus CHOP-like chemotherapy alone in young patients with good-prognosis diffuse large-B-cell lymphoma: a randomised controlled trial by the MabThera International Trial (MInT) Group," Lancet Oncology, vol. 7, no. 5, pp. 379-391, 2006.

[9] L. H. Sehn, B. Berry, M. Chhanabhai et al., "The revised International Prognostic Index (R-IPI) is a better predictor of outcome than the standard IPI for patients with diffuse large B-cell lymphoma treated with R-CHOP," Blood, vol. 109, no. 5, pp. 1857-1861, 2007.

[10] M. Ziepert, D. Hasenclever, E. Kuhnt et al., "Standard International prognostic index remains a valid predictor of outcome for patients with aggressive CD20+ B-cell lymphoma in the rituximab era," Journal of Clinical Oncology, vol. 28, no. 14, pp. 2373-2380, 2010.

[11] T. Philip, C. Guglielmi, A. Hagenbeek et al., "Autologous bone marrow transplantation as compared with salvage chemotherapy in relapses of chemotherapy-sensitive non-Hodgkin's lymphoma," New England Journal of Medicine, vol. 333, no. 23, pp. 1540-1545, 1995.

[12] L. F. Verdonck, W. L. J. Van Putten, A. Hagenbeek et al., "Comparison of chop chemotherapy with autologous bone marrow transplantation for slowly responding patients with aggressive non-Hodgkin's lymphoma," New England Journal of Medicine, vol. 332, no. 16, pp. 1045-1051, 1995.

[13] M. Martelli, M. Vignetti, P. L. Zinzani et al., "High-dose chemotherapy followed by autologous bone marrow transplantation versus dexamethasone, cisplatin, and cytarabine in aggressive non-Hodgkin's lymphoma with partial response to front-line chemotherapy: a prospective randomized Italian multicenter study," Journal of Clinical Oncology, vol. 14, no. 2, pp. 534-542, 1996.

[14] C. Haioun, E. Lepage, C. Gisselbrecht et al., "Survival benefit of high-dose therapy in poor-risk aggressive non-Hodgkin's lymphoma: final analysis of the prospective LNH87-2 protocol-a groupe d'etude des lymphomes de l'adulte study," Journal of Clinical Oncology, vol. 18, no. 16, pp. 3025-3030, 2000.

[15] H. C. Kluin-Nelemans, V. Zagonel, A. Anastasopoulou et al., "Standard chemotherapy with or without high-dose chemotherapy for aggressive non-Hodgkin's lymphoma: randomized 
phase III EORTC study," Journal of the National Cancer Institute, vol. 93, no. 1, pp. 22-30, 2001.

[16] N. Milpied, E. Deconinck, F. Gaillard et al., "Initial treatment of aggressive lymphoma with high-dose chemotherapy and autologous stem-cell support," New England Journal of Medicine, vol. 350, no. 13, pp. 1287-1295, 2004.

[17] A. M. Gianni, M. Bregni, S. Siena et al., "High-dose chemotherapy and autologous bone marrow transplantation compared with MACOP-B in aggressive B-cell lymphoma," New England Journal of Medicine, vol. 336, no. 18, pp. 1290-1297, 1997.

[18] G. Santini, L. Salvagno, P. Leoni et al., "VACOP-B versus VACOP-B plus autologous bone marrow transplantation for advanced diffuse non-Hodgkin's lymphoma: results of a prospective randomized trial by the non-Hodgkin's lymphoma cooperative study group," Journal of Clinical Oncology, vol. 16, no. 8, pp. 2796-2802, 1998.

[19] C. Gisselbrecht, E. Lepage, T. Molina et al., "Shortened firstline high-dose chemotherapy for patients with poor-prognosis aggressive lymphoma," Journal of Clinical Oncology, vol. 20, no. 10, pp. 2472-2479, 2002.

[20] U. Kaiser, I. Uebelacker, U. Abel et al., "Randomized study to evaluate the use of high-dose therapy as part of primary treatment for aggressive lymphoma," Journal of Clinical Oncology, vol. 20, no. 22, pp. 4413-4419, 2002.

[21] M. Martelli, F. Gherlinzoni, A. De Renzo et al., "Early autologous stem-cell transplantation versus conventional chemotherapy as front-line therapy in high-risk, aggressive nonHodgkin's lymphoma: an Italian multicenter randomized trial," Journal of Clinical Oncology, vol. 21, no. 7, pp. 12551262, 2003.

[22] A. Olivieri, G. Santini, C. Patti et al., "Upfront high-dose sequential therapy (HDS) versus VACOP-B with or without HDS in aggressive non-Hodgkin's lymphoma: long-term results by the NHLCSG," Annals of Oncology, vol. 16, no. 12, pp. 1941-1948, 2005.

[23] U. Vitolo, A. M. Liberati, M. G. Cabras et al., "High dose sequential chemotherapy with autologous transplantation versus dose-dense chemotherapy MegaCEOP as first line treatment in poor-prognosis diffuse large cell lymphoma: an "Intergruppo Italiano Linfomi" randomized trial," Haematologica, vol. 90, no. 6, pp. 793-801, 2005.

[24] D. C. Betticher, G. Martinelli, J. A. Radford et al., "Sequential high dose chemotherapy as initial treatment for aggressive sub-types of Non-Hodgkin Lymphoma: results of the international randomized phase III trial (MISTRAL)," Annals of Oncology, vol. 17, no. 10, pp. 1546-1552, 2006.

[25] D. C. Linch, L. Yung, P. Smith et al., "Final analysis of the UKLG LY02 trial comparing 6-8 cycles of CHOP with 3 cycles of CHOP followed by a BEAM autograft in patients $<65$ years with poor prognosis histologically aggressive NHL: research paper," British Journal of Haematology, vol. 149, no. 2, pp. 237243,2010 .

[26] S. H. Swerdlow, E. Campo, N. L. Harris et al., WHO Classification of Tumours of Haematopoietic and Lymphoid Tissues, WHO Press, 4th edition, 2008.

[27] C. Tarella, M. Zanni, M. Di Nicola et al., "Prolonged survival in poor-risk diffuse large B-cell lymphoma following front-line treatment with rituximab-supplemented, early-intensified chemotherapy with multiple autologous hematopoietic stem cell support: a multicenter study by GITIL (Gruppo Italiano Terapie Innovative nei Linfomi)," Leukemia, vol. 21, no. 8, pp. 1802-1811, 2007.
[28] U. Vitolo, A. Chiappella, E. Angelucci et al., "Dose-dense and high-dose chemotherapy plus rituximab with autologous stem cell transplantation for primary treatment of diffuse large Bcell lymphoma with a poor prognosis: a phase II multicenter study," Haematologica, vol. 94, no. 9, pp. 1250-1258, 2009.

[29] M. S. Dilhuydy, T. Lamy, C. Foussard et al., "Front-line highdose chemotherapy with Rituximab showed excellent longterm survival in adults with aggressive large B-cell lymphoma: final results of a phase II GOELAMS study," Biology of Blood and Marrow Transplantation, vol. 16, no. 5, pp. 672-677, 2010.

[30] O. Fitoussi, K. Belhadj, N. Mounier et al., "Survival impact of rituximab combined with ACVBP and upfront consolidative autotransplantation in high risk diffuse large B-cell lymphoma for GELA," Haematologica, vol. 96, pp. 1136-1143, 2011.

[31] P. J. Still, J. M. Unger, J. Cook et al., "Randomized phase III U.S./Canadian intergroup trial (SWOG S9704) comparing $\mathrm{CHOP} \pm \mathrm{R}$ for eight cycles to $\mathrm{CHOP} \pm \mathrm{R}$ for six cycles followed by autotransplant for patients with high-intermediate (H-int) or high IPI grade diffuse aggressive non-Hodgkin lymphoma," Journal of Clinical Oncology, vol. 29, abstract a8001, 2011.

[32] U. Vitolo, A. Chiappella, E. Brusamolino et al., "A randomized multicentre phase III study for first line treatment of young patients with high-risk (aaIPI 2-3) diffuse large B-cell lym-

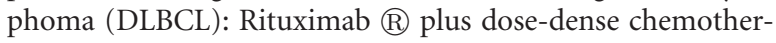
apy $\mathrm{CHOP} 14 / \mathrm{megaCHOP} 14$ with or without intensified highdose chemotheraly (HDC) and autologous stem cell transplantation (ASCT). Results of DLCL04 trial od Italian Lymphoma Foundation (FIL)," Annals of Oncology, vol. 22, supplement 4, a072, p. iv106, 2011.

[33] C. Guglielmi, F. Gomez, T. Philip et al., "Time to relapse has prognostic value in patients with aggressive lymphoma enrolled onto the parma trial," Journal of Clinical Oncology, vol. 16, no. 10, pp. 3264-3269, 1998.

[34] J. Y. Blay, F. Gomez, C. Sebban et al., "The International Prognostic Index correlates to survival in patients with aggressive lymphoma in relapse: analysis of the PARMA trial," Blood, vol. 92, no. 10, pp. 3562-3568, 1998.

[35] P. A. Hamlin, A. D. Zelenetz, T. Kewalramani et al., "Ageadjusted International Prognostic Index predicts autologous stem cell transplantation outcome for patients with relapsed or primary refractory diffuse large B-cell lymphoma," Blood, vol. 102, no. 6, pp. 1989-1996, 2003.

[36] T. Kewalramani, A. D. Zelenetz, S. D. Nimer et al., "Rituximab and ICE as second-line therapy before autologous stem cell transplantation for relapsed or primary refractory diffuse large B-cell lymphoma," Blood, vol. 103, no. 10, pp. 3684-3688, 2004.

[37] M. Sieniawski, O. Staak, J. P. Glossmann et al., "Rituximab added to an intensified salvage chemotherapy program followed by autologous stem cell transplantation improved the outcome in relapsed and refractory aggressive non-Hodgkin lymphoma," Annals of Hematology, vol. 86, no. 2, pp. 107-115, 2007.

[38] E. Vellenga, W. L. J. Van Putten, M. B. Van 't Veer et al., "Rituximab improves the treatment results of DHAP-VIMDHAP and ASCT in relapsed/progressive aggressive CD20+ NHL: a prospective randomized HOVON trial," Blood, vol. 111, no. 2, pp. 537-543, 2008.

[39] N. Mounier, C. Canals, C. Gisselbrecht et al., "High-dose therapy and autologous stem cell transplantation in first relapse for diffuse large B cell lymphoma in the rituximab era: an analysis based on data from the European Blood and 
Marrow transplantation registry," Biology of Blood and Marrow Transplantation. In press.

[40] A. Martín, E. Conde, M. Arnan et al., "R-ESHAP as salvage therapy for patients with relapsed or refractory diffuse large B-cell lymphoma: the influence of prior exposure to rituximab on outcome. A GEL/TAMO study," Haematologica, vol. 93, no. 12, pp. 1829-1836, 2008.

[41] T. S. Fenske, P. N. Hari, J. Carreras et al., "Impact of pretransplant rituximab on survival after autologous hematopoietic stem cell transplantation for diffuse large B cell lymphoma," Biology of Blood and Marrow Transplantation, vol. 15, no. 11, pp. 1455-1464, 2009.

[42] C. Gisselbrecht, B. Glass, N. Mounier et al., "Salvage regimens with autologous transplantation for relapsed large B-cell lymphoma in the rituximab era," Journal of Clinical Oncology, vol. 28, no. 27, pp. 4184-4190, 2010.

[43] I. F. Khouri, R. M. Saliba, C. Hosing et al., "Concurrent administration of high-dose rituximab before and after autologous stem-cell transplantation for relapsed aggressive B-cell non-Hodgkin's lymphomas," Journal of Clinical Oncology, vol. 23, no. 10, pp. 2240-2247, 2005.

[44] O. W. Press, J. F. Eary, F. R. Appelbaum et al., "Radiolabeledantibody therapy of B-cell lymphoma with autologous bone marrow support," New England Journal of Medicine, vol. 329, no. 17 , pp. 1219-1224, 1993.

[45] A. Krishnan, A. Nademanee, H. C. Fung et al., "Phase II trial of a transplantation regimen of yttrium-90 ibritumomab tiuxetan and high-dose chemotherapy in patients with nonHodgkin's lymphoma," Journal of Clinical Oncology, vol. 26, no. 1, pp. 90-95, 2008.

[46] J. N. Winter, D. J. Inwards, S. Spies et al., "Yttrium-90 ibritumomab tiuxetan doses calculated to deliver up to 15 Gy to critical organs may be safely combined with high-dose BEAM and autologous transplantation in relapsed or refractory B-cell non-hodgkin's lymphoma," Journal of Clinical Oncology, vol. 27, no. 10, pp. 1653-1659, 2009.

[47] A. A. Alizadeh, M. B. Eisen, R. E. Davis et al., "Distinct types of diffuse large B-cell lymphoma identified by gene expression profiling," Nature, vol. 403, no. 6769, pp. 503-511, 2000.

[48] A. Rosenwald, G. Wright, W. C. Chan et al., "The use of molecular profiling to predict survival after chemotherapy for diffuse large-B-cell lymphoma," New England Journal of Medicine, vol. 346, no. 25, pp. 1937-1947, 2002.

[49] G. Wright, B. Tan, A. Rosenwald, E. H. Hurt, A. Wiestner, and L. M. Staudt, "A gene expression-based method to diagnose clinically distinct subgroups of diffuse large B cell lymphoma," Proceedings of the National Academy of Sciences of the United States of America, vol. 100, no. 17, pp. 9991-9996, 2003.

[50] G. W. Van Imhoff, E. J. G. Boerma, B. Van Der Holt et al., "Prognostic impact of germinal center-associated proteins and chromosomal breakpoints in poor-risk diffuse large B-cell lymphoma," Journal of Clinical Oncology, vol. 24, no. 25, pp. 4135-4142, 2006.

[51] G. Lenz, G. Wright, S. S. Dave et al., "Stromal gene signatures in large-B-cell lymphomas," New England Journal of Medicine, vol. 359, no. 22, pp. 2313-2323, 2008.

[52] C. P. Hans, D. D. Weisenburger, T. C. Greiner et al., "Confirmation of the molecular classification of diffuse large B-cell lymphoma by immunohistochemistry using a tissue microarray," Blood, vol. 103, no. 1, pp. 275-282, 2004.

[53] W. W. L. Choi, D. D. Weisenburger, T. C. Greiner et al., "A new immunostain algorithm classifies diffuse large Bcell lymphoma into molecular subtypes with high accuracy," Clinical Cancer Research, vol. 15, no. 17, pp. 5494-5502, 2009.
[54] H. Nyman, M. Jerkeman, M. L. Karjalainen-Lindsberg, A. H. Banham, and S. Leppä, "Prognostic impact of activated Bcell focused classification in diffuse large B-cell lymphoma patients treated with R-CHOP," Modern Pathology, vol. 22, no. 8, pp. 1094-1101, 2009.

[55] G. Ott, M. Ziepert, W. Klapper et al., "Immunoblastic morphology but not the immunohistochemical GCB/nonGCB classifier predicts outcome in diffuse large B-cell lymphoma in the RICOVER-60 trial of the DSHNHL," Blood, vol. 116, no. 23, pp. 4916-4925, 2010.

[56] J. P. Jais, C. Haioun, T. J. Molina et al., "The expression of 16 genes related to the cell of origin and immune response predicts survival in elderly patients with diffuse large B-cell lymphoma treated with CHOP and rituximab," Leukemia, vol. 22, no. 10, pp. 1917-1924, 2008.

[57] C. Thieblemont, J. Briere, N. Mounier et al., "The germinal center/activated B-cell subclassification has a prognostic impact for response to salvage therapy in relapsed/refractory diffuse large B-cell lymphoma: a bio-CORAL study," Journal of Clinical Oncology, vol. 29, no. 31, pp. 4079-4087, 2011.

[58] K. Gu, D. D. Weisenburger, K. Fu et al., "Cell of origin fails to predict survival in patients with diffuse large B-cell lymphoma treated with autologous hematopoietic stem cell transplantation," Hematological Oncology. In press. 


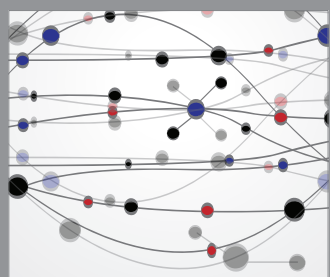

The Scientific World Journal
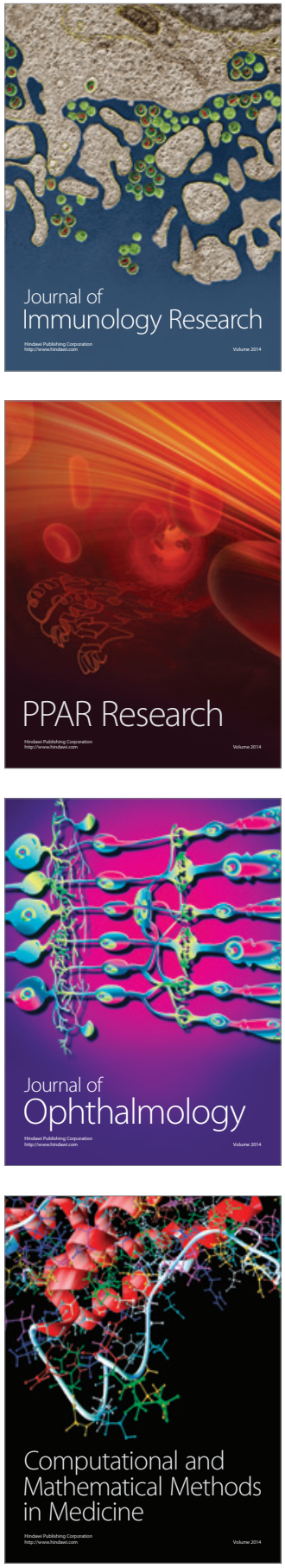

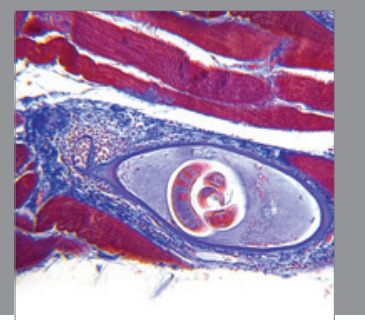

Gastroenterology

Research and Practice
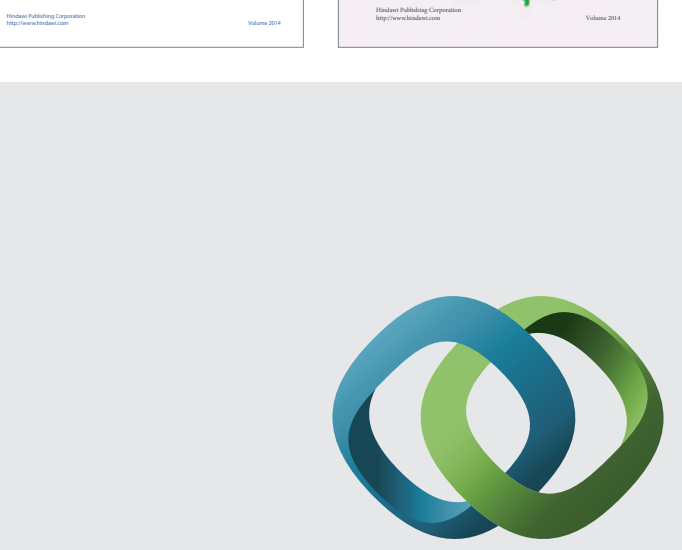

\section{Hindawi}

Submit your manuscripts at

http://www.hindawi.com
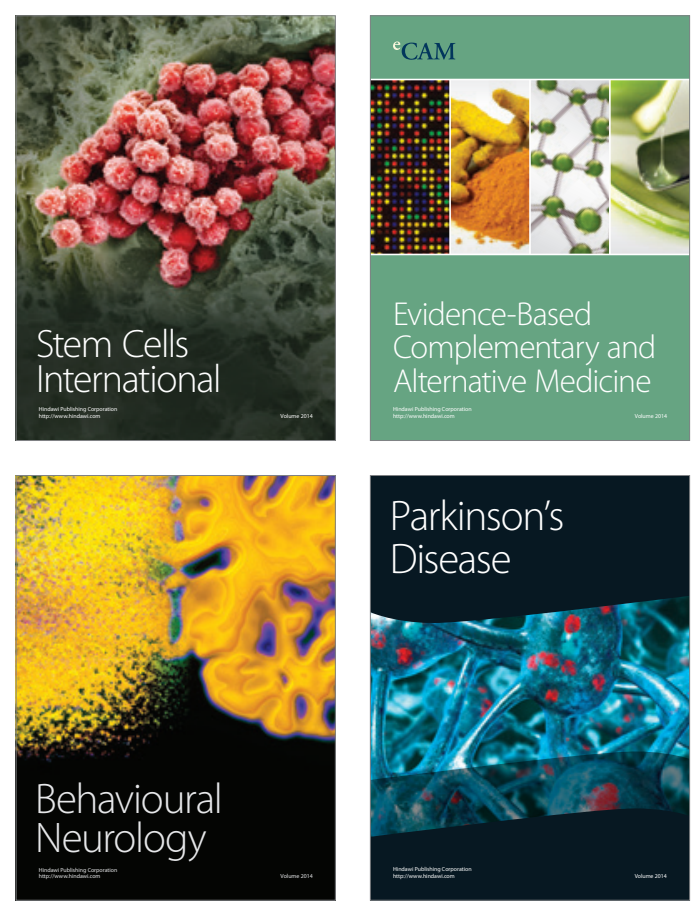

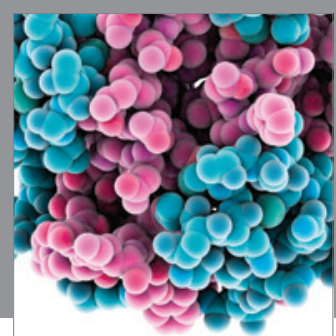

Journal of
Diabetes Research

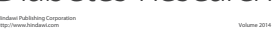

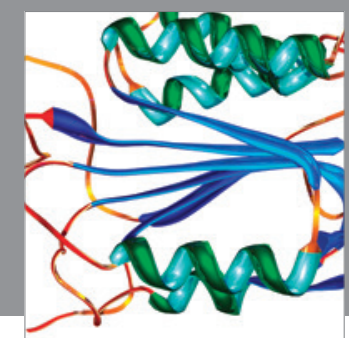

Disease Markers
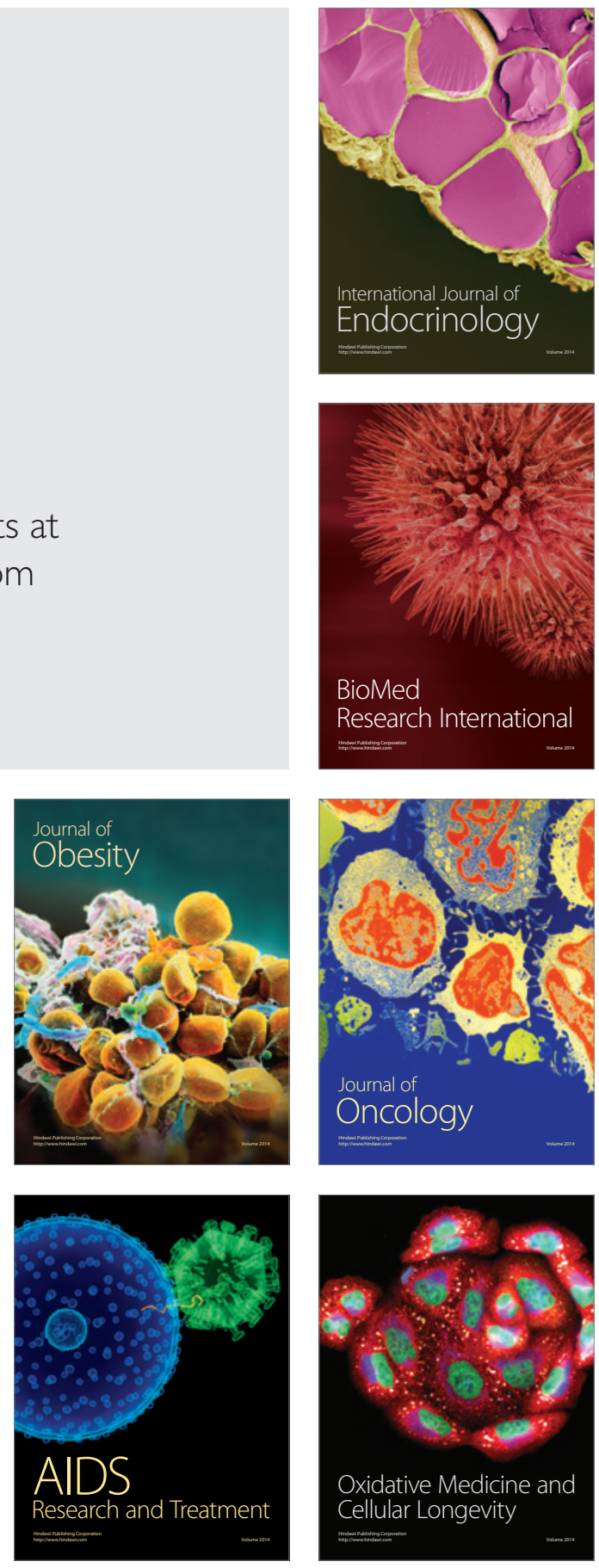